\title{
Short communication: Decrease in rumination time as an indicator of the onset of calving
}

\author{
S. Büchel ${ }^{1}$ and A. Sundrum \\ Department of Animal Nutrition and Animal Health, University of Kassel, 37213 Witzenhausen, Germany
}

\begin{abstract}
The aim of this study was to investigate whether rumination time (RT) is affected by the onset of calving. The relationship between both feeding time and dry matter intake (DMI) to the onset of calving was also examined. In addition, the correlation between feeding behavior characteristics, described here as RT, feeding time, and DMI, was evaluated. Under test conditions, the feeding behavior of pregnant Holstein cows was recorded from the time when they were moved into calving pens (usually 7 to 5 d prepartum) until the onset of calving. Feeding time and DMI were recorded by automatic feed bins; RT was measured continuously by a measuring halter based on electromyography (DairyCheck; BITSz Engineering GmbH, Zwickau, Germany), which constitutes a new approach regarding feeding behavior detection. Data analysis related to the final 72 $\mathrm{h}$, before the onset of calving, which were divided into twelve 6 -h blocks. The last $6 \mathrm{~h}$ (one 6 -h block) before calving were compared with the 72- to 7 -h time frame (11 times 6-h blocks) before calving, which was defined as the reference period. For this time period, feeding behavior data for 17 cows was fully available, which was the precondition for data analysis. In the final $6 \mathrm{~h}$ before imminent birth, RT was significantly reduced. During this time, it was found that the mean minimum RT was $69.9 \pm 28.5 \mathrm{~min} / 6 \mathrm{~h}$ compared with the mean RT of $95.5 \pm 30.8 \mathrm{~min} / 6 \mathrm{~h}$ in the reference period. The average decrease in RT was $27 \%$ ( $25.6 \mathrm{~min} / 6 \mathrm{~h}$ ). In addition, feeding time and DMI were significantly reduced. The average decrease in feeding time was $57 \%$ $(20.8 \mathrm{~min} / 6 \mathrm{~h})$, and in DMI it was $56 \%(1.9 \mathrm{~kg} / 6 \mathrm{~h})$. High correlation coefficients between feeding behavior characteristics were only found between feeding time and DMI. Values of feeding behavior among cows were characterized by high variability. Recording RT can serve as a useful tool for predicting the timing of birth for dairy cows, but further research is necessary.
\end{abstract}

Received October 16, 2013.

Accepted February 4, 2014

${ }^{1}$ Corresponding author: s.buechel@uni-kassel.de
Key words: birth, feeding behavior, management support, measurement system

\section{Short Communication}

The process of calving constitutes a critical stage for both dam and calf (Schuenemann et al., 2013). Prolonged calving, delayed parturition, or severe assisted extraction of the calf at birth can result in a difficult birth, which has been defined as dystocia (Mee, 2004; Lombard et al. 2007). Primary causes of dystocia are fetal-maternal size mismatch (Berger et al., 1992), fetal malpresentation (Meijering, 1984), dam-related causes such as uterine torsion (Frazer et al., 1996), and hypocalcemia (Curtis et al., 1983). Dystocia can lead to a range of consequences for the dairy cow and the calf, including an increased incidence of stillbirth (Meyer et al. 2000), calf mortality within $30 \mathrm{~d}$ postcalving (Lombard et al., 2007), an increased likelihood of both cow and calf respiratory and digestive disorders, and retained placenta and uterine disease of the cow (Lombard et al., 2003; Sheldon et al., 2009). Dystocia is also associated with economic losses due to a possible decrease in milk yield, decline in reproductive performance, and the risks for an increase in cow and calf morbidity and mortality (Dematawewa and Berger, 1997; Rajala and Gröhn, 1998). Prevention of dystocia in dairy cows should, therefore, be a high priority in farm management. Calving management practices for dairy personnel need to be adjusted to create optimal surveillance and care of the cow and calf during parturition. Wehrend et al. (2006) concluded from their results, which showed only minor differences between the behavior of cows with eutocia and dystocia, that the difference in behavior of cows and heifers during the first stage of labor should not be misconstrued as signs of dystocia. Therefore, recognition of benchmarks and reference times for normal births as well as for difficult births is essential for determining the appropriate time for intervention under field conditions (Schuenemann et al., 2013). This requires, if possible, an exact knowledge about the onset of birth. Thus, identification of the onset of birth is a crucial parameter for the prevention of dystocia. 
Generally, the onset of birth is recognized by monitoring behavior changes or external changes in the dam, either visually or by video observation (Miedema et al., 2011). Birth can also be monitored by measuring feeding behavior, such as feeding time and DMI (Lukas et al., 2008; Schirmann et al., 2013). Feeding time and DMI are reasonable and helpful indicators in the early recognition of animals that have deviated from their normal conditions (Beauchemin and Yang, 2005; De Vries et al., 2009; Burfeind et al., 2010). Monitoring short-term feeding behavior may particularly assist in the early identification of disorders (González et al., 2008). In dairy cows, a gradual depression in feeding time and DMI usually happens from a few days until a few hours before calving (Maekawa et al., 2002; Hansen et al., 2003). A decline in feeding behavior around calving may also be useful as potential indicator of dystocia (Proudfoot et al., 2009). Measuring feeding time and DMI on commercial dairy farms is laborious, dependent on human observation and is susceptible to human error (Lukas et al., 2008). In contrast, the measurement of individual rumination time (RT), which also belongs to feeding behavior characteristics, is more suitable for automatic, sensor-based recording. Rumination time is associated with feeding time and DMI (Yang and Beauchemin, 2006; Adin et al., 2009), lying time (Beauchemin, 1991; Schirmann et al., 2012), and time of estrus (Reith and Hoy, 2012). Recent studies also indicate a relationship with the onset of calving (Soriani et al., 2012; Schirmann et al., 2013). Contrary to feeding behavior, RT is simpler to record and, therefore, easier to use for monitoring dairy cows. As a result, numerous methods for automatically measuring, assessing, and analyzing individual RT of dairy cows have been developed up to now (Ungar and Rutter, 2006; Schirmann et al., 2009; Burfeind et al., 2011).

The overall objective of this study was to investigate whether an obvious decrease in RT exists shortly before calving. The aims were to (1) measure the individual $\mathrm{RT}$ in the last $72 \mathrm{~h}$ before calving and (2) determine if RT might be a useful indicator for predicting the timing of birth. Furthermore, feeding time and DMI were recorded to assess their relationship with calving time and RT.

The study was conducted under test conditions at the Saxony-Anhalt State Institute for Agriculture, Forestry and Horticulture (Iden, Germany) from June to August 2013. A total of 55 multiparous Holstein cows were tested. The cows used varied in lactation number $(3.8 \pm 1.9 ;$ mean $\pm \mathrm{SD})$ and age $(62.9 \pm 22.2$; mean \pm $\mathrm{SD})$. From 7 to $5 \mathrm{~d}$ before the expected date of calving, a maximum of 12 cows were held in a straw-bedded calving pen with a size of $5.4 \mathrm{~m}^{2}$ per cow. Most of the cows used calved on their own; $18 \%$ were assisted during the calving process. The cows had free access at any time to 5 feed bins (Bavarian State Institute for Agriculture, Freising-Weihenstephan, Germany). When a cow approached the feed bin, an antenna detected its unique neck collar-mounted transponder and lowered the barrier, allowing the cow access to the feed. Dairy cows were given a TMR ad libitum once per day at approximately $1000 \mathrm{~h}$ comprising $34.0 \%$ lucerne grass silage, $44.2 \%$ corn silage, and $21.8 \%$ concentrate and mineral mix on a basis of $45.0 \%$ DM. Feeding time and DMI were recorded by using automatic feed bins from the day of being moved into the calving pen until the onset of calving. The equipment was serviced once per year by trained staff. The automatic feed bins were validated at least once each year by external specialized staff (Bavarian State Institute for Agriculture). The RT of each cow was measured by a measuring halter (DairyCheck; BITSz Engineering GmbH, Zwickau, Germany). The investigated cows were used to wearing these halters at least $5 \mathrm{~d}$ before they were moved to the calving pen, but without data recording. When the cows were moved to the calving pen once per week, measurement halters were applied again. The effect of regrouping was not measured during this study. After calving, cows were moved to the fresh milking pen and measurement halters were removed. The RT was recorded from the day of halter application until a few hours after calving. The onset of calving was recognized by human observation of changes in the cows' behavior or on the basis of external changes, or both. Cows were observed at least once per hour by 1 of 5 different trained observers. The main changes in behavior which were determined were signs of lifting the tail and restlessness. From this point, the amount of feed intake and duration of feeding time and RT were analyzed for the previous $72 \mathrm{~h}$. During analysis, measurement values recorded within these 72 $\mathrm{h}$ were divided into twelve 6 - $\mathrm{h}$ blocks. The reference period was defined as the last $66 \mathrm{~h}$ (11 times 6-h blocks) before the last $6 \mathrm{~h}$ (one 6 -h block) before the onset of calving. And the onset of calving was defined as the hour when the first stage of the expulsion period was detected by visual observation. Data relating to 17 of the 55 cows tested were available for this study. Only fully generated data sets of feeding behavior could be considered for the analysis. The main reason for the lack of data from 38 of the dairy cows was the incidence of premature delivery after being moved into the calving pen, which meant that it was not always possible to use the measuring halter for the $3 \mathrm{~d}$ necessary for this study. A further reason was due to the fact that some of the rumination and feed bin data were missing.

For the automatic recording of RT, an electromyography (EMG)-based system labeled as DairyCheck (BITSz Engineering GmbH) was used. The continuous 
measurement of feeding behavior by electromyography thus offers a completely new and innovative approach. It is a sensor-based system for monitoring the rumination and feeding time of dairy cows (our unpublished data). The system comprises a measurement halter with 2 incorporated electrodes, a data logger, a power supply, and evaluation software. The myoelectrodes are closely attached to the skin of the cow for measuring electrical impulses of the musculus masseter. They are connected to a data logger, which registers the electrical impulses with a resolution of 600 measuring points per minute and saves them to a mobile central data processing unit for up to $11 \mathrm{~h}$. Direct raw data transmission takes place live via bidirectional radio transmission (BITSz Engineering $\mathrm{GmbH}$ ) at a frequency of $2.4 \mathrm{GHz}$ to 2 antennas positioned beside the calving pen. The read range of the antenna is 50 to $75 \mathrm{~m}$. Thereby, live observation and constant monitoring of feeding behavior in real time is possible. For validation, the feeding behavior of 14 cows for each minute, as determined by both the EMG system and visual observation, was analyzed (our unpublished data). Correspondence between measurements of direct visual observation and continuous measurements generated electronically by EMG was assessed for the total time spent ruminating within the observed periods of 311 to 422 min using the Bland and Altman plot (Bland and Altman, 1986) in Figure 1. The Bland and Altman method included plotting the average of paired measurements (x-axis) achieved by direct visual observation and by the EMG system against their difference (y-axis). The 95\% confidence interval of the mean of the difference was calculated and covered on the plot. The total number of agreements (a) and disagreements (d) for electronic recording and visual observation of feeding time and RT were used to calculate an index of concordance [i.e., a/ $(\mathrm{a}+\mathrm{d})$; Martin and Bateson, 1986]. The overall index of concordance was $87 \%$ and showed adequate agreement of the results of both assessments. The system is powered by a rechargeable 3.7-V, 2.7-Ah lithium-ion battery, which allows up to 3 wk of uninterrupted recordings. Data are evaluated in terms of graphs. The generated data can be used for distinguishing between active feeding and rumination phases and inactive dormant phases. Because the analysis software for achieving the automatic classification of feeding behavior is still under development, data are processed manually by the researchers themselves. Two researchers were involved in interpreting the data graphs, whereby no transmission errors and disagreements appeared between them. Interobserver agreement between both independent observers was very high $(\mathrm{r}=$ $0.98 ; \mathrm{n}=83 ; P<0.001)$.
Statistical data analysis was accomplished with the SPSS program (version 20.0.0; IBM Co. Inc., Armonk, NY). Data were summarized for each cow at 6-h intervals. Hours with incomplete data due to technical problems or premature calving were discarded. Only dairy cows with at least $72 \mathrm{~h}$ of data until onset of calving (n $=17$ cows) were included in the final analysis. Descriptive statistics were used for all variables. The data were normally distributed and assessed by the KolmogorovSmirnov test. The 6 -h intervals from 72 to $7 \mathrm{~h}$ before the onset of calving were calculated within cow and compared for each of the cows individually. From these data, a mean across the 17 cows was calculated. Means of the reference period against the 6 - $\mathrm{h}$ period before calving were tested by using the univariate ANOVA with repeated measurements. The relationship between feeding behavior characteristics was assessed using the Pearson correlation coefficient (Pearson, 1920). A level of confidence of $95 \%$ was applied.

The duration of rumination time of dairy cows was influenced by calving time (Figure 2). Fifteen out of $17(88 \%)$ of the dairy cows analyzed showed reduced RT during the last $6 \mathrm{~h}$ before calving. In the reference period, cows spent, on average, $95.5 \pm 30.8 \mathrm{~min} / 6 \mathrm{~h}$ ruminating. During the last $6 \mathrm{~h}$ before the onset of calving, RT averaged $69.9 \pm 28.5 \mathrm{~min} / 6 \mathrm{~h}$. The RT was significantly reduced $(P<0.01)$ by a mean of $27 \%$ $(25.6 \mathrm{~min} / 6 \mathrm{~h})$ in the last $6 \mathrm{~h}$ before the onset of calving compared with the reference period. With respect to all 17 cows, the variance of RT within the reference period ranged from a maximum of 210.5 to $0 \mathrm{~min} / 6$ $\mathrm{h}$. Within the last $6 \mathrm{~h}$ before the onset of calving, the variance of RT ranged from a maximum of 114.8 to 0 $\min / 6 \mathrm{~h}$.

Feeding time (Figure 3) and DMI (Figure 4) were influenced by onset of calving. Sixteen out of 17 cows (94\%) spent less time feeding and all 17 (100\%) cows reduced DMI in the last $6 \mathrm{~h}$ before the onset of calving. Cows spent an average of $36.4 \pm 18.6 \mathrm{~min} / 6 \mathrm{~h}$ feeding and had a mean DMI of $3.5 \pm 1.8 \mathrm{~kg} / 6 \mathrm{~h}$ within the reference period. During the last $6 \mathrm{~h}$ before the onset of calving, feeding time was $15.6 \pm 12.6 \mathrm{~min} / 6 \mathrm{~h}$ and DMI was $1.6 \pm 1.1 \mathrm{~kg} / 6 \mathrm{~h}$. Both feeding time and DMI were significantly reduced $(P<0.001)$ by, on average, $57 \%(20.8 \mathrm{~min} / 6 \mathrm{~h})$ and by a mean of $56 \%(1.9 \mathrm{~kg} / 6 \mathrm{~h})$ within the last $6 \mathrm{~h}$ before the onset of calving compared with the reference period.

The variance of all 17 cows ranged from 115.5 to 0 $\min / 6 \mathrm{~h}$ for feeding time and from 11.9 to $0 \mathrm{~kg} / 6 \mathrm{~h}$ for DMI within the reference period. For the last $6 \mathrm{~h}$ before the onset of calving, the variance ranged from 49.5 to $0 \mathrm{~min} / 6 \mathrm{~h}$ for feeding time and from 3.8 to $0 \mathrm{~kg} / 6 \mathrm{~h}$ for DMI. 


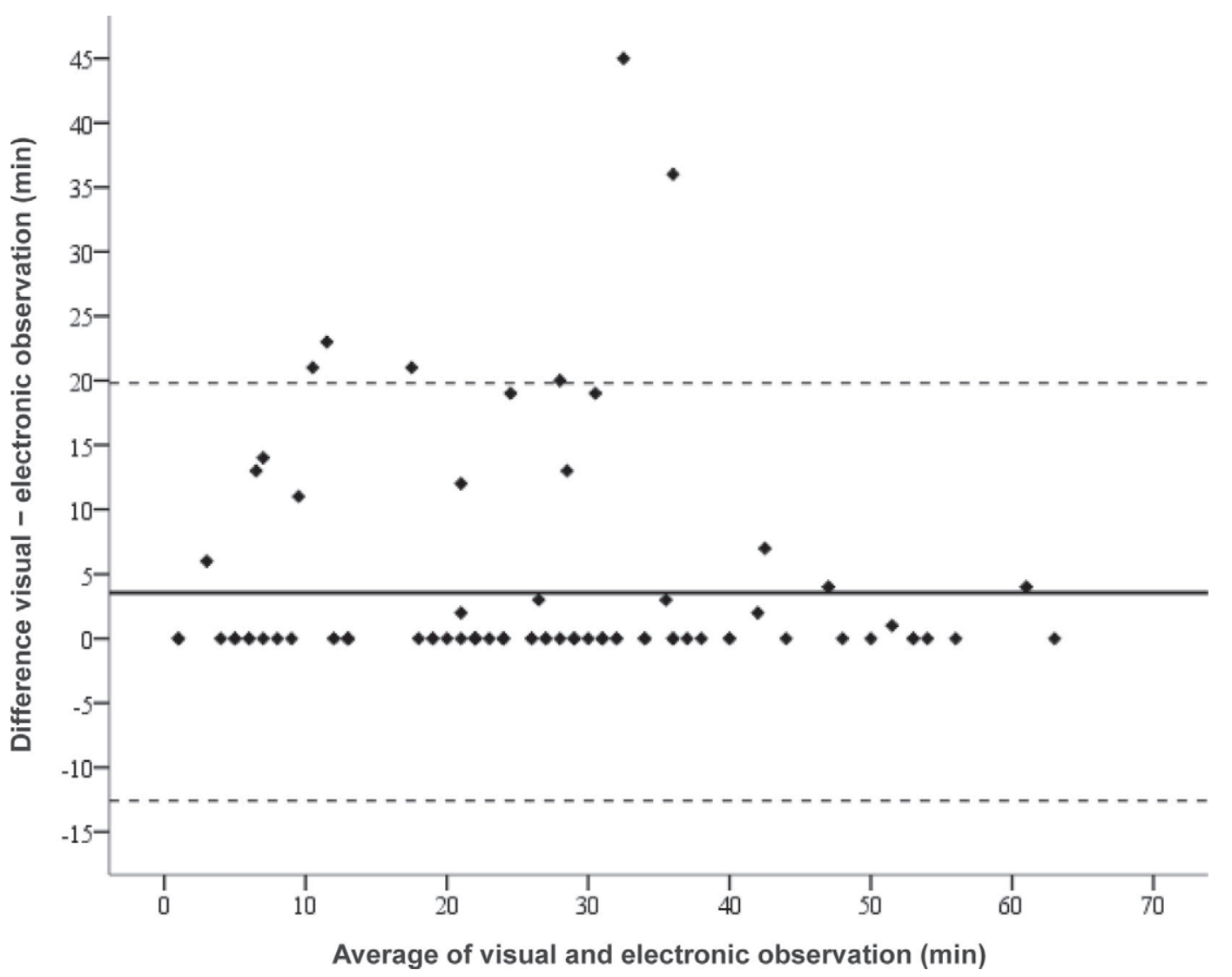

Figure 1. Differences between rumination times measured electronically by electromyography (EMG) and by direct visual observation (visual - electronic) against the mean of both estimates. Data are shown for 83 rumination periods from 14 cows [mean difference $=3.56 ; 95 \%$ CI (horizontal dashed lines): -12.6 to 19.8$]$.

Associations between parameters of feeding behavior were different. Periods of $72 \mathrm{~h}$ each were used for the calculation of these correlations. Correlation coefficients $(\mathrm{r})$ and coefficients of determination $\left(\mathrm{R}^{2}\right)$ between feeding time and DMI were on a high level $\left(\mathrm{r}=0.81 ; \mathrm{R}^{2}=\right.$ $0.66 ; \mathrm{n}=17 ; P<0.01$ ). However, between feeding time and RT, the correlation was weak $\left(\mathrm{r}=-0.085 ; \mathrm{R}^{2}=\right.$ 0.007; $P>0.05$ ) and not significant. Even between RT and DMI only a slight relationship existed in terms of a low, but significant negative correlation $\left(\mathrm{r}=-0.19 ; \mathrm{R}^{2}\right.$ $=0.035 ; P<0.01)$.

The current results of the relationship between rumination time and calving time are in agreement with results that have been reported in previous studies (Adin et al., 2009; Soriani et al. 2012; Schirmann et al. 2013). All results demonstrate that RT was significantly influenced by the onset of calving. However, neither Adin et al. (2009) nor Soriani et al. (2012) detected changes in the feeding behavior in relation to calving time. Adin et al. (2009) observed the lowest daily RT (less than $200 \mathrm{~min} / \mathrm{d}$ ) during parturition. Soriani et al. (2012) recorded a strong reduction of RT around calving with the lowest RT values of $262 \mathrm{~min} / \mathrm{d}$ in primiparous and $278 \mathrm{~min} / \mathrm{d}$ in pluriparous cows. Schirmann et al. (2013) observed an average decrease in RT of $63 \pm 30 \mathrm{~min} / 24$ $\mathrm{h}$ in the last 24 -h period before calving. The cause of the large variation in RT between these studies might be the great differences in the NDF content of the rations. The NDF content of $56.6 \%$ of the diet during dry period used in the study of Soriani et al. (2012) differed considerably from the NDF content of $29.4 \%$ of the prepartum TMR used in the studies of Schirmann et al. (2013) and Adin et al. (2009; NDF experimental group: $31.4 \%$; NDF control group: $32.5 \%$ ). The differences in fiber content partly explain the differences in feeding behavior. Therefore, different studies have shown a major effect of NDF (Beauchemin and Yang, 2005; Adin et al., 2009) and roughage intake (Rotger et al., 2006) or particle size (Krause and Combs, 2003) on feeding and rumination time.

Exact classification of the onset of calving is difficult, because behavioral changes vary considerably; thus, comprehensive training in calving management practices is necessary (Schuenemann et al., 2013). This fact 


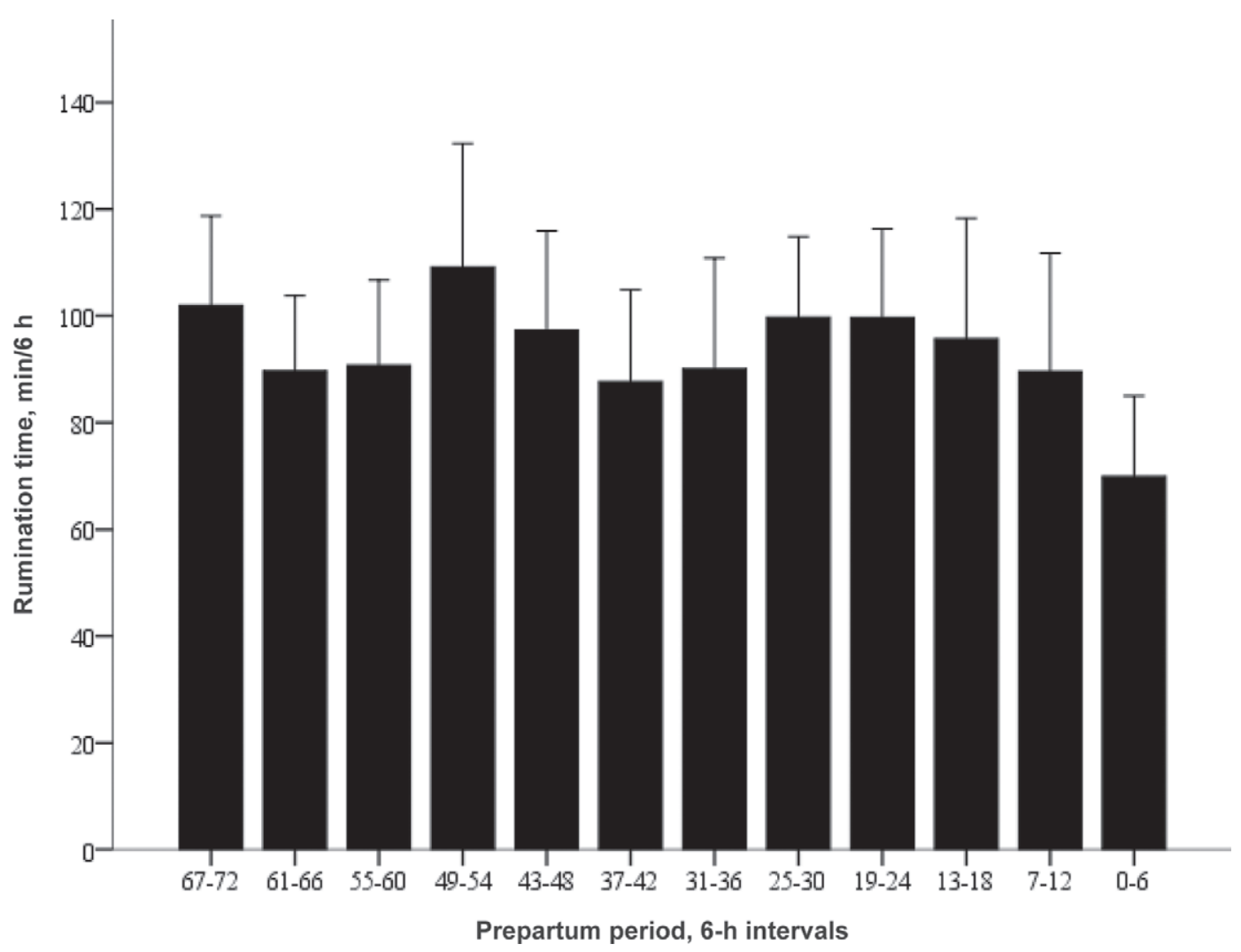

Figure 2. Variance in rumination time of dairy cows $(\mathrm{min} / 6 \mathrm{~h})$ during the last $72 \mathrm{~h}$ before the onset of calving (mean and $\mathrm{SD} ; \mathrm{n}=17)$.

may lead to the imprecise determination of the exact onset of calving and explains a possible shift in the last $6 \mathrm{~h}$ before calving.

In the current study, feeding time and DMI were also significantly influenced by the onset of calving. Reduction in feeding time and DMI is consistent with results of other studies. Bertics et al. (1992) recorded a reduction of $30 \%$ in DMI during the final week before calving. Journet and Remond (1976) observed a decrease of $0.2 \mathrm{~kg}$ of voluntary DMI per week during the last 6 wk of pregnancy. In the study of Proudfoot et al. (2009), the DMI of cows with dystocia decreased by approximately $25 \%$ in the last $24 \mathrm{~h}$ before calving and the DMI of cows with eutocia decreased by approximately $33 \%$ in the last $24 \mathrm{~h}$ before calving, both compared with $2 \mathrm{~d}$ before calving. This decline in DMI confirms the results of the current study, irrespective of whether or not the cows were suffering from dystocia. During the last week of pregnancy, the days of lowest DMI were the day before calving and the actual day of calving. Lukas et al. (2008) observed a decrease in DMI and water intake, which was associated with the time of calving. According to Dado and Allen (1994), feeding time is strongly associated with DMI, which is in accordance with the previous results. Urton et al. (2005) observed a decrease in time spent feeding of $35 \%$ over the final 2 wk before calving. In the study of Huzzey et al. (2007), cows decreased feeding time in the last 2 wk before calving. The last two studies looked more at changes in feeding behavior in relation to diseases, which may provide evidence that feeding behavior is not solely explained by the onset of calving. The objectives of the study of Schirmann et al. (2013) were to describe changes in feeding behavior around calving. They detected a decrease of feeding behavior shortly before parturition which partly confirms the results of the current study.

The prepartum reduction in feeding time and DMI may be due to physical limitations related to pregnancy, as mentioned by Oetzel and Berger (1985), or to the hormonal status of the cow (Hansen et al., 2003). Rumination time may also be affected by these factors, although no physiological explanations currently exist. But regrouping may also have affected the feeding behavior patterns shortly before calving. Regrouping may reduce the clear and significant decline in feeding behavior. Regrouping is known to have a profound effect on feeding and social behavior and production in the hours and days following regrouping (von Keyserlingk et al., 2008). Considering that feeding time and 


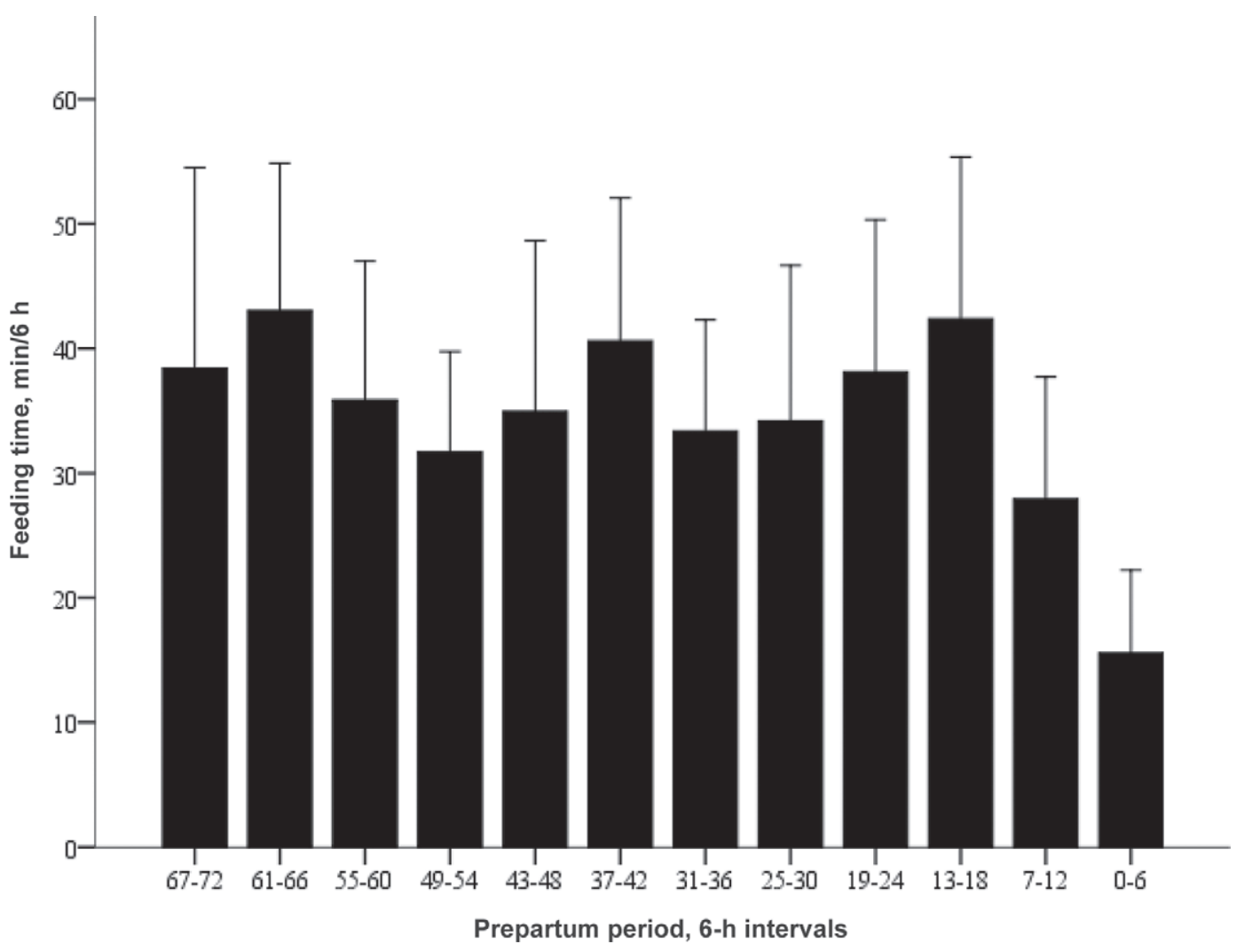

Figure 3. Variance in feeding time of dairy cows $(\mathrm{min} / 6 \mathrm{~h})$ during the last $72 \mathrm{~h}$ before the onset of calving $($ mean and $\mathrm{SD} ; \mathrm{n}=17)$.

DMI are strongly associated with RT (Welch, 1982; Dado and Allen, 1994; Yang and Beauchemin, 2006), the demand for chewing the cud is reduced when feed intake decreases. However, due to the low correlation between DMI and RT, a reduced feed intake does not adequately explain the reduced RT. On the other hand, RT may be reduced by endocrine changes shortly before calving. The estrogen concentration constitutes a diverse indicator for altered behavioral changes. A positive correlation between estrous behavior and total estrogen concentration $(\mathrm{r}=0.66 ; P<0.0019)$ has been observed by Mondal et al. (2006). This raised estrogen concentration during estrus affects feed intake and activity behavior (Phillips and Schofield, 1990; Arney et al., 1994), which are both negatively correlated with RT (Mondal et al., 2006). Besides decreased feed intake and increased activity, in addition, an increase in estrogen levels (Falter, 1999) exists shortly before calving, whereby RT might be affected.

Not all animals showed a decrease in RT and feeding time during the $6 \mathrm{~h}$ before onset of calving. Dry matter intake, however, was affected in all dairy cows. Variability of feeding behavior was calculated between cows. Rumination time varied from +31 to $-100 \%$, feeding time from +24 to $-100 \%$, and DMI from -15 to $-100 \%$ among dairy cows. These results indicate high variability between different cows.

A weak negative correlation was observed between RT and feeding time and between RT and DMI. These results are comparable with those found by Schirmann et al. (2012). A negative relationship between RT and feeding time and DMI confirms the assumption that cows which ruminate more spend less time feeding, and that cows are not able to consume feed and ruminate at the same time (Van Soest, 1994; Schirmann et al., 2012). Statements of Welch (1982) and Dado and Allen (1994) about the strong positive relationship between feeding time and DMI to RT could not be confirmed.

Within the last $6 \mathrm{~h}$ before the onset of calving, RT was significantly reduced compared with the reference period, which included the 72- to 7 -h period before calving. Feeding time and DMI were also, on average, significantly reduced shortly before calving compared with the reference period. Thus, RT can be used as an early indicator for predicting the timing of birth. Although feeding time and DMI also indicate an approaching birth, they require extensive equipment for the assessment of changes in cow behavior due to imminent delivery. Overall, the results of the relationship between RT and calving time constitute a new oppor- 


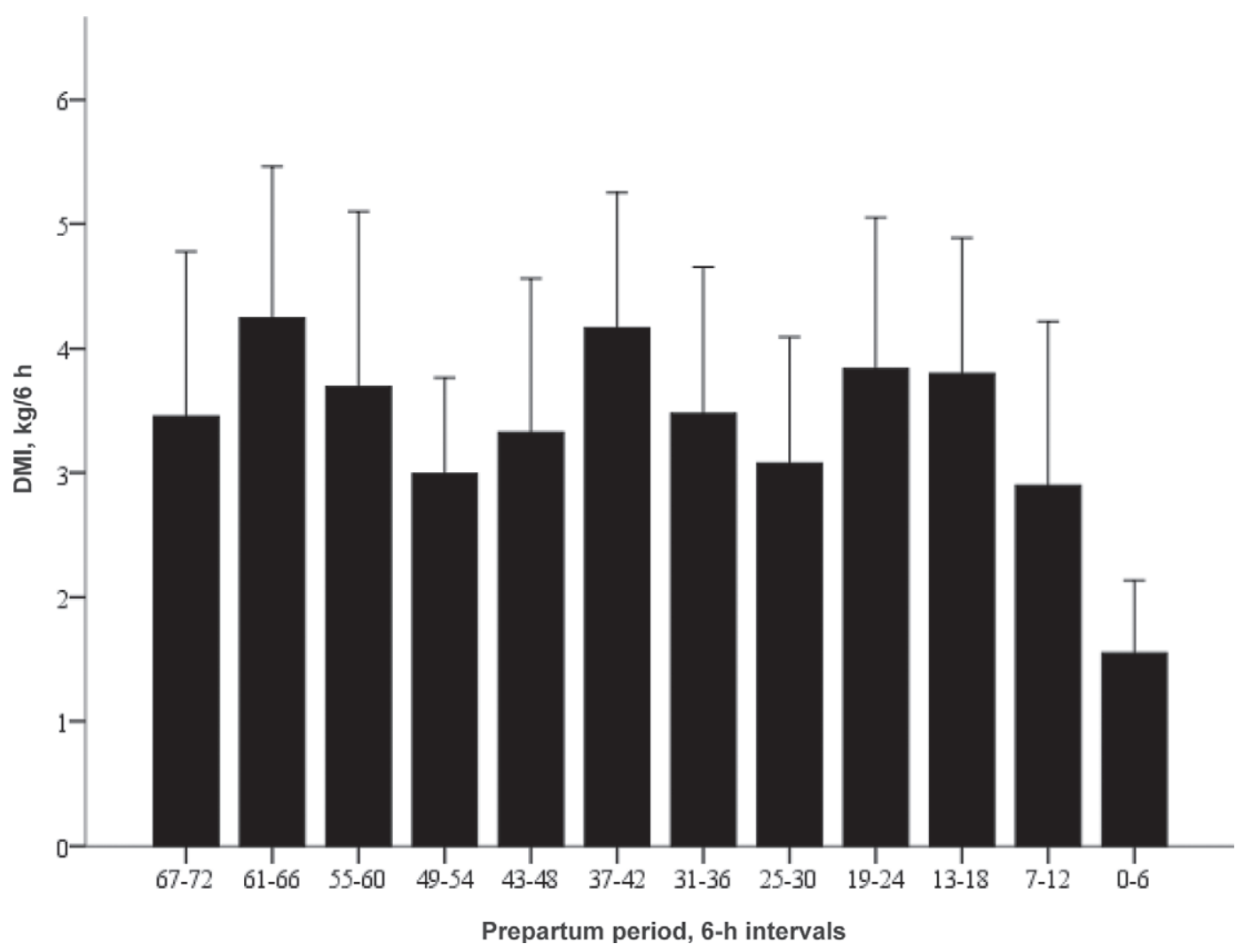

Figure 4. Variance in DMI of dairy cows $(\mathrm{kg} / 6 \mathrm{~h})$ during the last $72 \mathrm{~h}$ before the onset of calving (mean and SD; $\mathrm{n}=17)$.

tunity for predicting the timing of calving. However, further research is necessary to define accuracy, repeatability, sensitivity, and specificity of generated data with a larger number of dairy cows kept under various conditions to determine suitable, individual-animal reference values for RT decrease before the onset of calving.

\section{ACKNOWLEDGMENTS}

We thank the State Institute for Agriculture, Forestry and Horticulture Saxony-Anhalt (Iden, Germany) for accomplishment of the trial at their farm. This trial was implemented during the project "NutriCheck," which was funded by the Federal Office for Agriculture and Food (BLE, Bonn, Germany) and the Federal Ministry of Food, Agriculture and Consumer Protection (BMELV, Berlin, Germany).

\section{REFERENCES}

Adin, G., R. Solomon, M. Nikbachat, A. Zenou, E. Yosef, A. Brosh, A. Shabtay, S. J. Mabjeesh, I. Halachmi, and J. Miron. 2009. Effect of feeding cows in early lactation with diets differing in roughageneutral detergent fiber content on intake behavior, rumination, and milk production. J. Dairy Sci. 92:3364-3373.
Arney, D. R., S. E. Kitwood, and C. J. C. Phillips. 1994. The increase in activity during oestrus in dairy cows. Appl. Anim. Behav. Sci. 40:211-218.

Beauchemin, K. A. 1991. Ingestion and mastication of feed by dairy cattle. Vet. Clin. North Am. Food Anim. Pract. 7:439-463.

Beauchemin, K. A., and W. Z. Yang. 2005. Effects of physically effective fiber on intake, chewing activity, and ruminal acidosis for dairy cows fed diets based on corn silage. J. Dairy Sci. 88:2117-2129.

Berger, P. J., A. C. Cubas, K. J. Koehler, and M. H. Healey. 1992 Factors affecting dystocia and early calf mortality in Angus cows and heifers. J. Anim. Sci. 70:1775-1786.

Bertics, S. J., R. R. Grummer, C. Cadorniga-Valino, and E. E. Stoddard. 1992. Effect of prepartum dry matter intake on liver triglyceride concentration and early lactation. J. Dairy Sci. 75:19141922.

Bland, J. M., and D. G. Altman. 1986. Statistical methods for assessing agreement between two methods of clinical measurement. Lancet 1:307-310.

Burfeind, O., K. Schirmann, M. A. G. von Keyserlingk, D. M. Veira, D. M. Weary, and W. Heuwieser. 2011. Technical note: Evaluation of a system for monitoring rumination in heifers and calves. J. Dairy Sci. 94:426-430.

Burfeind, O., P. Sepúlveda, M. A. G. von Keyserlingk, D. M. Weary, D. M. Veira, and W. Heuwieser. 2010. Technical note: Evaluation of a scoring system for rumen fill in dairy cows. J. Dairy Sci. 93:3635-3640.

Curtis, C. R., H. N. Erb, C. J. Sniffen, R. D. Smith, P. A. Powers, M. C. Smith, M. E. White, R. B. Hillman, and E. J. Pearson. 1983. Association of parturient hypocalcemia with eight periparturient disorders in Holstein cows. J. Am. Vet. Med. Assoc. 183:559-561.

Dado, R. G., and M. S. Allen. 1994. Variation in and relationships among feeding, chewing, and drinking variables for lactating dairy cows. J. Dairy Sci. 77:132-144. 
Dematawewa, C. M. B., and P. J. Berger. 1997. Effect of dystocia on yield, fertility, and cow losses and an economic evaluation of dystocia scores for Holsteins. J. Dairy Sci. 80:754-761.

DeVries, T. J., K. A. Beauchemin, F. Dohme, and K. S. SchwartzkopfGenswein. 2009. Repeated ruminal acidosis challenges in lactating dairy cows at high and low risk for developing acidosis: Feeding, ruminating and lying behavior. J. Dairy Sci. 92:5067-5078.

Falter, K. 1999. In vitro-Untersuchungen zur Bildung und Metabolisierung konjugierter Östrogene in der Rinderplazenta während der Gravidität und unter der Geburt. Doctoral Diss. Justus-LiebigUniversität Gießen.

Frazer, G. S., N. R. Perkins, and P. D. Constable. 1996. Bovine uterine torsion: 164 hospital referral cases. Theriogenology 46:739-758.

González, L. A., B. J. Tolkamp, M. P. Coffey, A. Ferret, and I. Kyriazakis. 2008. Changes in feeding behavior as possible indicators for the automatic monitoring of health disorders in dairy cows. J. Dairy Sci. 91:1017-1028.

Hansen, S. S., P. Nørgaard, C. Pedersen, R. J. Jørgensen, L. S. B. Mellau, and J. D. Enemark. 2003. The effect of subclinical hypocalcaemia induced by $\mathrm{Na}_{2}$-EDTA on the feed intake and chewing activity of dairy cows. Vet. Res. Commun. 27:193-205.

Huzzey, J. M., D. M. Veira, D. M. Weary, and M. A. G. von Keyserlingk. 2007. Prepartum behavior and dry matter intake identify dairy cows at risk for metritis. J. Dairy Sci. 90:3220-3233.

Journet, M., and B. Remond. 1976. Physiological factors affecting the voluntary intake of feed by cows: A review. Livest. Prod. Sci. $3: 129-146$.

Krause, K. M., and D. K. Combs. 2003. Effects of forage particle size, forage source, and grain fermentability on performance and ruminal $\mathrm{pH}$ in midlactation cows. J. Dairy Sci. 86:1382-1397.

Lombard, J. E., F. B. Garry, S. M. Tomlinson, and L. P. Garber. 2003. Relationship of dystocia to dairy cow health and productivity. J. Dairy Sci. 86(Suppl. 1):32.

Lombard, J. E., F. B. Garry, S. M. Tomlinson, and L. P. Garber. 2007. Impacts of dystocia on health and survival of dairy calves. J. Dairy Sci. 90:1751-1760.

Lukas, J. M., J. K. Reneau, and J. G. Linn. 2008. Water intake and dry matter intake changes as a feeding management tool and indicator of health and estrus status in dairy cows. J. Dairy Sci. 91:3385-3394.

Maekawa, M., K. A. Beauchemin, and D. A. Christensen. 2002. Effect of concentrate level and feeding management on chewing activities, saliva production and ruminal $\mathrm{pH}$ of lactating dairy cows. J. Dairy Sci. 85:1165-1175.

Martin, P., and P. Bateson. 1986. Measuring Behaviour: An Introductory Guide. Cambridge University Press, Cambridge, UK.

Mee, J. F. 2004. Managing the dairy cow at calving time. Vet. Clin. North Am. Food Anim. Pract. 20:521-546.

Meijering, A. 1984. Dystocia and stillbirth in cattle-A review of causes, relations and implications. Livest. Prod. Sci. 11:143-177.

Meyer, C. L., P. J. Berger, and K. J. Koehler. 2000. Interactions among factors affecting stillbirths in Holstein cattle in the United States. J. Dairy Sci. 83:2657-2663.

Miedema, H. M., M. S. Cockram, C. M. Dwyer, and A. I. Macrae 2011. Behavioural predictors of the start of normal and dystocia calving in dairy cows and heifers. Appl. Anim. Behav. Sci. 131:14-19.

Mondal, M., C. Rajkhowa, and B. S. Prakash. 2006. Relationship of plasma estradiol-17 $\beta$, total estrogen, and progesterone to estrus behavior in Mithun (Bos frontalis) cows. Horm. Behav. 49:626633
Oetzel, G., and L. L. Berger. 1985. Protein-energy related malnutrition in domestic ruminants. Part 1. Predisposing factors and pathophysiology. Comp. Cont. Educ. Pract. Vet. 7:S672-S679.

Pearson, K. 1920. Notes on the history of correlation. Biometrika 13:25-45

Phillips, C. J. C., and S. A. Schofield. 1990. The effect of environment and stage of the oestrous cycle on the behaviour of dairy cows. Appl. Anim. Behav. Sci. 27:21-31.

Proudfoot, K. L., J. M. Huzzey, and M. A. G. von Keyserlingk. 2009 The effect of dystocia on the dry matter intake and behavior of Holstein cows. J. Dairy Sci. 92:4937-4944.

Rajala, P. J., and Y. T. Gröhn. 1998. Effects of dystocia, retained placenta, and metritis on milk yield in dairy cows. J. Dairy Sci. 81:3172-3181.

Reith, S., and S. Hoy. 2012. Relationship between daily rumination time and estrus of dairy cows. J. Dairy Sci. 95:6416-6420.

Rotger, A., A. Ferret, X. Manteca, J. L. Ruiz de la Torre, and S. Calsamiglia. 2006. Effects of dietary nonstructural carbohydrates and protein sources on feeding behavior of tethered heifer fed highconcentrate diets. J. Anim. Sci. 84:1197-1204.

Schirmann, K., N. Chapinal, D. M. Weary, W. Heuwieser, and M. A. G. von Keyserlingk. 2012. Rumination and its relationship to feeding and lying behavior in Holstein dairy cows. J. Dairy Sci. 95:3212-3217.

Schirmann, K., N. Chapinal, D. M. Weary, L. Vickers, and M. A. G. von Keyserlingk. 2013. Short communication: Rumination and feeding behavior before and after calving in dairy cows. J. Dairy Sci. 96:7088-7092.

Schirmann, K. M. A. G. von Keyserlingk, D. M. Weary, D. M. Veira, and W. Heuwieser. 2009. Technical note: Validation of a system for monitoring rumination in dairy cows. J. Dairy Sci. 92:6052-6055.

Schuenemann, G. M., S. Bas, E. Gordon, and J. D. Workman. 2013. Dairy calving management: Description and assessment of a training program for dairy personnel. J. Dairy Sci. 96:2671-2680.

Sheldon, I. M., J. Cronin, L. Goetze, G. Donofrio, and H.-J. Schuberth. 2009. Defining postpartum uterine disease and the mechanisms of infection and immunity in the female reproductive tract in cattle. Biol. Reprod. 81:1025-1032.

Soriani, N., E. Trevisi, and L. Calamari. 2012. Relationships between rumination time, metabolic conditions, and health status in dairy cows during the transition period. J. Anim. Sci. 90:4544-4554.

Ungar, E. D., and S. M. Rutter. 2006. Classifying cattle jaw movements: Comparing IGER Behaviour Recorder and acoustic techniques. Appl. Anim. Behav. Sci. 98:11-27.

Urton, G., M. A. G. von Keyserlingk, and D. M. Weary. 2005. Feeding behavior identifies dairy cows at risk for metritis. J. Dairy Sci. 88:2843-2849.

Van Soest, P. J. 1994. Nutritional Ecology of the Ruminant. Cornell University Press, Ithaca, NY

von Keyserlingk, M. A. G., D. Olenick, and D. M. Weary. 2008. Acute behavioral effects of regrouping dairy cows. J. Dairy Sci. 91:10111016.

Wehrend, A., E. Hofmann, K. Failing, and H. Bostedt. 2006. Behaviour during the first stage of labour in cattle: Influence of parity and dystocia. Appl. Anim. Behav. Sci. 100:164-170.

Welch, J. G. 1982. Rumination, particle size and passage from the rumen. J. Anim. Sci. 54:885-894.

Yang, W. Z., and K. A. Beauchemin. 2006. Effects of physically effective fiber on chewing activity and ruminal $\mathrm{pH}$ of dairy cows fed diets based on barley silage. J. Dairy Sci. 89:217-228. 